\title{
Discourse Presentation as an Index of Style: A Comparative Corpus Stylistic Analysis of Self and Other Translators
}

\author{
Zara Obaid $^{1}$, Muhammad Asim Mahmood ${ }^{1}$ Javed Iqbal $^{2} \&$ Maryam Zahoor $^{1}$ \\ ${ }^{1}$ Department of Applied Linguistics, Government College University, Faisalabad, Pakistan \\ ${ }^{2}$ University of Gujrat, Pakistan \\ Correspondence: Muhammad Asim Mahmood, Department of Applied Linguistics, Government College \\ University, Faisalabad, Pakistan. E-mail: masimrai@gmail.com; zaraobaid3@gmail.com; \\ javediqbal188@hotmail.com; maryamzahooralam@gmail.com
}

Received: August 30, 2017 Accepted: September 25, 2017 Online Published: October 25, 2017

doi:10.5539/ijel.v8n1p119 URL: https://doi.org/10.5539/ijel.v8n1p119

\begin{abstract}
This study aims to explore the style of other and self-translators in comparison with non-translated texts, assuming discourse presentation as an indicator of style. Theoretically, other and self-translators are considered different in their translation style. The reason is that self-translators enjoy more liberty and authority over the source text as compared to other-translators (Bozkurt, 2014; Cordingley, 2013). However, practically, previous studies have explored either the style of self-translators (Ehrlich, 2009) or other-translators (Saldanha, 2011). None of the studies has provided a comparison among these types. The current study is a pioneer in establishing general styles of self and other-translators. It explores three categories of literary texts i.e., by self-translators, other-translators and by Pakistani writers. Each category further comprises of three representative texts. They are, then, processed through AntConc 3.4.4 and tagged manually. The model of speech, writing and thought presentation proposed by Semino \& Short (2004) based on Leech \& Short's (1981) model is used, as it encompasses all the presentation techniques employed in literary texts. Frequencies acquired through tagging are then normalized and results are presented in the form of graphs. Findings of the research reveal that both other and self-translators are character-oriented in their style. However, other-translators are more objective and reader-oriented with less interference from the narrator. In contrast, self-translators are more subjective with more intervention from the narrator. These results are significant for further researches concerning self and other-translators.
\end{abstract}

Keywords: comparative corpus stylistics, discourse presentation, other translator, self-translator, speech presentation, thought presentation, writing presentation

\section{Introduction}

Stylistic study of literary texts is a widespread notion with several researchers determining the general styles of authors on the basis of these texts. However, with the birth of translation studies this notion of style also began to tantalize the researchers in this field. As a result, initially this idea of translator's style was repelled with an argument of invisibility of translators; nevertheless, the works by certain researchers like Baker (2000) made it mainstream. Several studies have been conducted on the style of translators where some used statistical patterns like type-token ratio or average sentence length etc. (ibid.) to determine style; others explored style at a lexical level through collocations for example (Bernardini, 2007); whereas still others explored at sentential or pragmatic level through transitivity, modality and discourse presentation (Bosseaux, 2004). This particular study will focus on discourse presentation to determine the style of self and other-translation categories.

Discourse presentation comprises of speech, thought and writing presentation and "focuses on segmental level" (Kuusi, 2016, p. 1). Numerous researches have been conducted on discourse presentation in order to determine the style of translators (Bosseaux, 2004, 2004; Kuusi, 2016; Winters, 2005), however, they just focus on one or two subtypes or categories of discourse presentation. A very few researches employ discourse presentation category as a whole. Huang (2015), for example, discussed all discourse presentation scales but his corpus lacked self-translations and comprised only of an original with its three translations. Hence, as none of the studies discussed style, particularly discourse presentation style, of self and other-translators side by side in its entirety, therefore, this research will be a pioneer in characterizing the general style of self and other-translators. 
Moreover, in contrast to all the previous studies that used parallel corpora, this study will use a monolingual comparable corpus since it has an advantage, over parallel model, of identifying "patterning which is specific to translated texts, irrespective of the source or target languages involved" (Baker, 1995, p. 234).

The major purpose of this study is to explore all discourse presentation categories in self and other-translators and to characterize their general style based on it. It also aims at exploring the difference of style among translated and non-translated texts. For this purpose, the current study examined three text categories i.e. other-translators, self-translators and Pakistani writers and tagged them manually using Semino and Short's (2004) framework of discourse presentation based on Leech \& Short's (1981) model as it deals with all the modes of presentation employed in texts. However, given the scope of this research, the left most type of each presentation scale which lies on the narrator's end i.e. NV, NW and NI are not discussed in this research based on the assumption that these types were absent from Leech \& Short's (1981) model and still each presentation scale elucidated the style of literary texts rigorously. Moreover, the results of this research are significant for future researchers interested in the field of translation studies. As they provide general patterns for self and other-translators, therefore, they can be compared against new findings from future researches.

\section{Review of the Literature Relevant to the Study}

Translation studies being an interdiscipline (Snell-Hornby, Pochhacker, \& Kaindl, 1994) have expanded across various fields including linguistics, culture, history and stylistics. Recently, the use of corpus stylistics for the study of literary and non-literary corpora has garnered a lot of attention. According to McIntyre (2015), corpus stylistics can be defined as "the application of theories, models and frameworks from stylistics in corpus analysis" (p. 61). The strength of corpus stylistics lies in the fact that it incorporates corpus-based quantitative methods to analyze stylistic features qualitatively, hence, striking a perfect balance between quantitative and qualitative approaches (Ho, 2011). Therefore, style of large corpora in translation studies, as the one used in this research, can be studied easily by using quantification methods as a means rather than an end.

Style in translation studies has begun from the notion of "translator's invisibility" (Venuti, 1995) with all the focus on the style of "original" writing and its transference to the relevant translation. Later Hermans (1996), Schiavi (1996) and Baker (2000) presented the concept of translator's voice and style in a translated narrative. According to Hermans (1996), translator's voice is more or less explicitly always present in a translated narrative. However, it is only discernible when it breaks through the text and appears on the surface e.g., through paratextual intervention. Correspondingly, Schiavi (1996) demonstrates that from a narratological point of view, a translation is different from the original owing to the presence of translator who is the first reader of a text and well aware of implied reader. Baker (2000), in contrast, uses a more practical approach and defines style as thumbprints of a translator expressed via linguistic and non-linguistic features. Hence, style of a translator includes "preferred or recurring patterns of linguistics behavior" (p. 245) rather than a chance intervention. As far as this study is concerned, it also discusses style from Baker's perspective where frequent patterns in a text category constitute its style.

The concept of translator's style further brings into consideration two types of translations as per the status of translator i.e., other-translation and self-translation. Self-translation is defined as "the translation of an original work into another language by the author himself" (Popovič, 1976, p. 19) in contrast to other-translation where translator is anybody but author himself. The difference in the two translations lies in the fact that "self translation typically produces another "version" or a new "original" of a text" (Cordingley, 2013, p. 2) because of the notion of faithfulness and authority of self-translator over an "original" work (Bozkurt, 2014). Moreover, unlike other-translators, self-translators undergo a double writing process rather than two-stage process of reading and writing (Fitch, 1988), thus, giving them more liberty in their translations as compared to other-translators. However, these claims are not supported by any empirical evidence, therefore, this study tries to generate styles of self and other-translators based on the empirical evidence.

Apart from linguistic features, translator's style can also be determined by a peculiar point of view from which a narrative is presented. Few researchers like Bosseaux (2007) and Munday (2008) have observed a shift in the point of view of translation as a result of certain choices made by translators. One such aspect that affects the point of view of a translation is choices made in the presentation of speech and thought of characters. Kvantaliani (2014) has shown in her research that variations between speech and thought presentation categories can manipulate the reader response as well as the narrative point of view. Different authors place these techniques of speech and thought presentation in different planes/categories of point of view. As per Upensky (1973) point of view consists of four planes: (i) Ideological (ii) Phraseological (iii) Spatial and temporal (iv) Psychological. In his view phraseological plane concerns “[the] author's choices with regard to the presentation 
of speech and thought". Simpson (as cited in Bosseaux, 2007), in contrast, considers the techniques of speech and thought presentation to "straddle the gap between spatio-temporal point of view and psychological point of view" (p. 27). This study will discuss the effect of discourse presentation, which encompasses speech and thought presentation, on point of view and ultimately style of translators.

A lot of studies have been conducted which depict a shift of point of view in translation as a result of translator's choices of speech and thought presentation. Bosseaux (2004) in her study on free indirect discourse (FID) in To the Lighthouse and The Waves and their corresponding French translations shows that in translations FID are less accentuated and sometimes converted into indirect sentences or direct discourse. Hence, the enunciative heterogeneity characteristic of FID which includes a blend of character and narrator's voice is lost. Also, it results in a shift in "feel" of translations as boundaries between characters voice and that of narrator become more marked, giving dominance to narrator's voice in the most of the cases. Similarly, Kuusi (2016) in her research on Crime and Punishment with its Finnish translations shows that the addition of reporting clause and substitution of third person pronoun with a first person pronoun in translations of FID exemplifies the normalization and explicitation strategies of universals of translation. She examined that FID is converted into direct discourse, thus supporting the normalization universal of translation. Contrarily, the use of reporting clause converted it into an indirect discourse, thus supporting the explicitation universal of translation. Moreover, this is done on the part of translator, consciously or unconsciously, in order to enhance the readability of the text. Furthermore, this conversion of FID ultimately leads to a change in the point of view of the text.

This study differs from the above mentioned researches as they are solely based on translations of a single text. They try to develop style of particular translators but none of the studies aim to generate a general style of translators. This research, however, presents a comparative analysis of the style of self-translators and other-translators in comparison with Pakistani writers through the use of monolingual comparable model. Moreover, it will help probe general trends of discourse presentation in these categories as well as their effect on point of view and translators' style.

\section{Theoretical Framework}

This research analyzes various discourse presentation categories from our given corpus of Pakistani fiction in order to understand the writing style of self and other-translators in comparison to non-translated works. Therefore, the theoretical framework underpinning this study is discourse presentation model proposed by Semino \& Short (2004) based on Leech \& Short's (1981) model.

Leech \& Short (1981) are considered pioneers of differentiating systematically between speech and thought presentation categories in prose fiction. For this purpose they proposed two different but parallel scales of speech and thought presentation categories with narrative report of speech and thought acts on the left-most end of the continuum and free direct speech and thought on the right-most end. On the contrary, the norms for both scales of presentation are different. These horizontal scales of presentation are given below (where $[\mathrm{N}]$ stands for narration and involves no speech or though presentation, hence, it is optional):

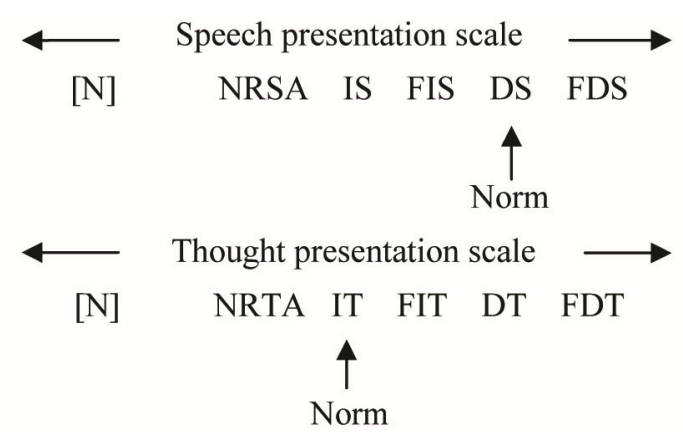

Figure 1. Speech and thought presentation scales and their respective norms (Semino \& Short, 2004, p. 15)

It can be noted that although the scales are parallel and similar but each category of speech and thought presentation has a different effect owing to the difference in norms of each scale. As the norm for speech presentation scale is direct speech, therefore, a move away from DS to the left-hand side results in increasing authorial intervention owing to the movement towards the narrator end of scale. Therefore, FIS is the first category in which reader feels that narrator directly intervenes in the speech of character. This intervention of 
author/narrator increases as we go further left. In contrast, the norm for thought presentation is indirect thought because thoughts cannot be directly perceived. As a result, FIT category makes the reader feel closer to the thought process of character.

Based on Leech \& Short's (1981) model, Semino \& Short (2004) proposed a revised model of discourse presentation which is applicable to not only fiction but other narrative genres as well. This revised model differs from Leech \& Short's (1981) model in two major ways i.e., it consists of an additional writing presentation scale parallel to speech and thought presentation scales as well as an additional category is added to the left end of each scale between narration [N] and NRSA/NRTA. According to this model each text is broadly analyzed based on three modes of presentation:

1) Speech presentation

2) Thought presentation

3) Writing presentation

Each mode of presentation has six further categories but only five categories common to Leech \& Short's (1981) model will be analyzed in this research as per our scope. As these categories lie on the parallel scales arranged across a continuum depicting degrees of narratorial intervention, therefore, these categories have a lot in common. The only difference being that speech presentation categories use "tell-type verbs" (Huang, 2015, p. 64) thought presentation use "think-type verbs" (ibid., p. 65) and writing presentation categories use write-type verbs. So, in order to show their commonalities these categories for speech, though and writing presentation will be grouped together and explained below:

\subsection{The Direct Categories}

In direct categories of presentation, words are quoted verbatim and "include deictic words appropriate to the anterior speech, thought or writing event being presented" (McIntyre et al., 2004, p.59). As far as the structure of direct categories is concerned, it consists of a reporting clause as well as a reported clause placed between quotation marks.

\subsection{The Free Direct Categories}

In order to produce free forms of direct category either quotation marks of reported clause or reporting clause is removed or both of these features are removed. This produces freer form where narrator intervention is reduced further.

\subsection{The Indirect Categories}

In indirect categories of presentation, words are not quoted but "one expresses what was said in one's own words" (Leech \& Short, 1981, p. 255). Structurally, it consists of a reported clause which is grammatically subordinated to a reporting clause through the use of that, if etc. as a subordinating conjunction. It includes deictic features which are "appropriate to the speaker in the posterior, discourse presenting, situation" (McIntyre et al., 2004, p.60).

\subsection{The Free Indirect Categories}

Free Indirect categories are identified by a combination of "deictic, syntactic and lexical features, some appropriate to current speaker, others to the producer of the anterior speech, writing or thought event being presented" (McIntyre et al., 2004, p. 60). Structurally, they are complex as they lack associated reporting clauses and involve the use of past tense with third person pronouns.

\subsection{Narrative Representation of Speech/Thought/Writing Act}

This category merely reports that a speech act has occurred but "the narrator does not have to commit himself entirely to giving the sense of what was said" (Leech \& Short, 1981, p. 259). Structurally, it consists of speech act verbs often followed by noun phrases or prepositional phrases which summarize the content of the utterance (Semino \& Short, 2004).

This research employs Semino \& Short's (2004) model because fiction not only presents speech and thought of its characters but, sometimes, also incorporates epistolary way of writing to reveal about its characters or plot. Hence, to analyze the discourse presentation of our corpus in its entirety, this model of speech, thought and writing was used.

\section{Research Methodology}

In this research a corpus of Pakistani translated and non-translated fiction is analyzed qualitatively through 
discourse presentation model proposed by Semino \& Short (2004).

\subsection{Sample}

The corpus of Pakistani fiction used in this research is self-compiled and is organized on the basis of monolingual comparable model (Baker, 1993). It is selected based on convenience sampling so that the data can be handled easily and aptly. The corpus is divided into three categories i.e., Pakistani writers, self-translators and other-translators in order to make a comparison among these categories. Each category consists of further three novels. The Pakistani writers category is comprised of "Blasphemy", "Ice Candy Man" and "The Stone Woman". Self-translators category consists of "River of Fire", "The Sun that Rose from the Earth" and "Weary Generation" whereas Other-translators category constitutes "Godavari", "The Sea Lies Ahead" and "Umrao Jan Ada". Moreover, the whole corpus comprises of 975561 words/tokens.

\subsection{Tools}

The researchers used AntConc 3.4.4 as a tool for analyzing corpus and generating lists for each discourse presentation type.

\subsection{Corpus Annotation}

In order to tag the corpus, a system of annotation was used to make our tagging consistent across tagging by various researchers. To make our annotation system easy to remember and applicable, acronyms of these subtypes were used to tag data. This system was inspired from Semino \& Short's (2004) SW\&TP tagset (p. 235). Table 1 mentions the system of annotation used for this research.

Table 1. Annotation system for discourse presentation categories

\begin{tabular}{ll}
\hline Category/Acronym & Definition \\
\hline DS & Direct speech \\
DT & Direct thought \\
DW & Direct writing \\
FDS & Free direct speech \\
FDT & Free direct thought \\
FDW & Free direct writing \\
IS & Indirect speech \\
IT & Indirect thought \\
IW & Indirect writing \\
FIS & Free indirect speech \\
FIT & Free indirect thought \\
FIW & Free indirect writing \\
NRSA & Narrator's representation of speech acts \\
NRTA & Narrator's representation of thought acts \\
NRWA & Narrator's representation of writing acts \\
\hline
\end{tabular}

\subsection{Method of Analysis}

As each category mentioned above was analyzed differently, therefore, their peculiar method of analysis is given below:

\subsubsection{Method of Analysis for Direct and Free Direct Categories}

In order to find out these particular categories from the corpus, a regular expression was developed and applied by using "Regex" tool of AntConc 3.4.4. This tool helped to locate all the quoted text between quotation marks

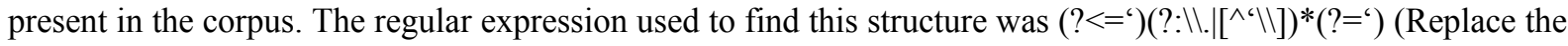
commas in this regular expression with the commas of your text if it does not work). Once the quoted text was located, it was generated into excel sheets and then each sentence was tagged manually. The clue for direct categories included the presence of a reporting clause before, after or in-between the reported clause (quoted text). Further, the type of reporting verb used i.e., tell-type, think-type or write-type verb classified it into DS, DT or DW.

As far as free direct category is concerned, the same data generated in the excel sheets using the regular expression was used and those sentences were tagged as free direct that did not have any kind of reporting verb but solely contained the reported clause. Moreover, the context of that reported clause revealed whether it was a FDS, FDT or FDW. 


\subsubsection{Method of Analysis for Indirect and Free Indirect Categories}

In order to find out these categories, separate lists of reporting verbs for speech, thought and writing were used to tag the data. The reporting verbs were taken from Semino \& Short (2004, pp. 237-245) and each verb was used with its past participle as well as third person present form (-s) to encompass all the instances of that reporting verb in the corpus. Corpus was analyzed in AntConc 3.4.4 by using a regular expression of $\backslash \mathrm{b}(---) \backslash \mathrm{b}$ where "---“" inside the parenthesis was substituted by the lists of reporting verbs of speech, thought and writing. Moreover, the results generated were copied into excel files and then each sentence was tagged manually.

As far as indirect form is concerned, the clue for its identification was the presence of a reporting clause and a reported clause grammatically subordinated by the use of subordinate conjunctions or a reporting clause with another clause having third person pronouns and third forms of the verb. In contrast, identification of free indirect forms is completely context dependent. Its basic clue was the absence of a reporting clause and presence of third person pronouns with a past tense and sometimes use of "close" deictic words (e.g. here, now, this etc.). Context reading in this case varied from reading one previous sentence to three or four paragraphs back.

\subsubsection{Method of Analysis for Narrative Representation of Speech/Thought/Writing Act}

In order to find out this category, speech act verbs lists were generated as speech act verbs are an integral part of this category. For this purpose, Searle's (1976) taxonomy of speech act verbs consisting of representatives, directives, commissives, expressives and declaratives was used and a separate list was generated for each. Moreover, their lists taken from Vanderveken (1990) are given in the Appendix A.

\subsection{Computation of Frequencies}

Initially, raw frequencies were generated by manually tagging the lists produced through the processes discussed in previous subsection. These raw frequencies were then turned into normalized frequencies in order to bring about a comparison across the three text categories of varying lengths. As the tagged data were structures rather than tokens, therefore, raw frequencies were adjusted per 1000 sentences. For this purpose, raw frequencies were divided by total number of sentences in a text and were multiplied by 1000 . Moreover, in order to compute normalized frequency for a whole category of texts individual normalized frequencies of each text were added.

\section{Results}

This study aims to explore the effect of choice of discourse presentation categories on the style of other-translators (Other Transl.) and self-translators (Self Transl.). The texts selected for these categories are originally written as well as translated by various novelists from Pakistan and India. Therefore, in order to evaluate their style in its true sense these categories are further benchmarked against non-translated English novels written by Pakistani writers (Paki. Writers). Moreover, the results of this study will help to determine in particular the style of Pakistani other and self-translators as well as a more general style of other and self-translators.

This section will present a comparative analysis of normalized frequencies of each discourse presentation category i.e. speech, thought and writing used among other-translators, self-translators and Pakistani writers. But before dealing with each category individually, figure 2 presents an overall normalized frequency usage of all discourse presentation types in the three categories of texts. The graph shows that although some of the types majorly contribute in determining the style of both other and self-translators, still a number of anomalies exist. 


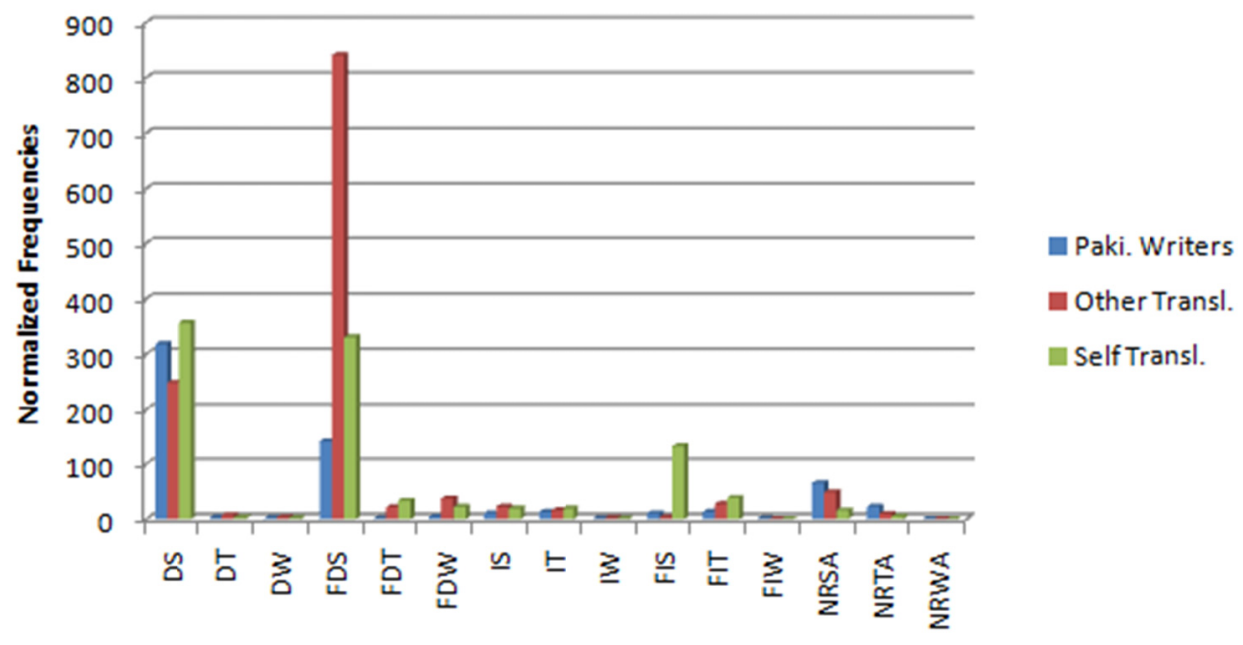

Figure 2. Comparison of all discourse presentation types across Paki. Writers, Other Transl. and Self Transl

Figure 2 reveals that DS and FDS are the most widely used forms of discourse presentation whereas NRSA is the third most frequent type across all the three text types. As far as FIS is concerned, the pattern looks highly inconsistent where the bar of self-translators stands out as compared to others being negligible. Therefore, this should be taken as an exception. Besides, taking into consideration all types of writing presentation it becomes clear that except FDW all other types are razed to the x-axis. The reason for this low frequency is that writing presentation is the least employed discourse presentation form in literary texts as authors rely on more conventional forms of speech and thought to build the narrative. Similarly, the representation of DT in the graph is next to nothing since it is the most artificial way of representing thoughts. Moreover, it can also be observed that both IS and IT seem to have almost similar frequencies. This figure shows that generally both translated and non-translated Pakistani texts employ same types of discourse presentation, however, the difference lies in their relative usage. Hence, the style of other and self-translators will be established on their relative differences. This graph also depicts that more than half of the corpus is comprised of speech presentation as the two most frequent types i.e. DS and FDS fall under speech presentation. Figure 3 demonstrates normalized frequencies of speech, thought and writing presentation categories in the three categories of corpus.

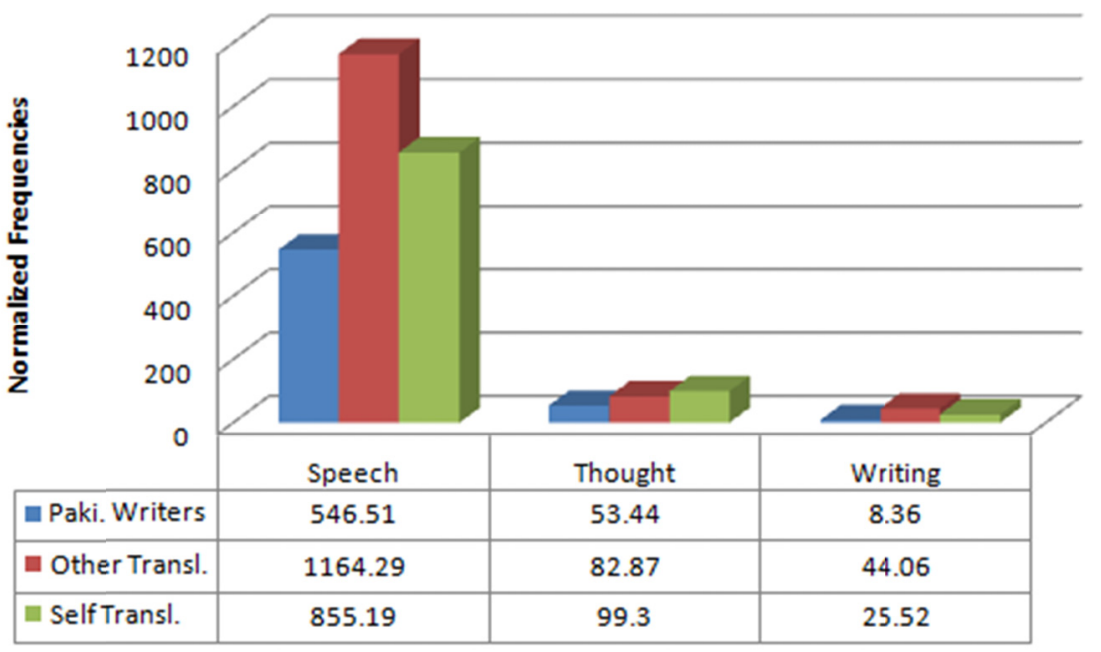

Figure 3. Comparison of SW\&TP across Paki. Writers, Other Transl. and Self Transl

Figure 3 shows that thought presentation is the second most frequent category of discourse presentation employed in literary texts, following speech presentation. It also depicts that speech and writing presentation follow a similar pattern of other-translators comprising the most number of speech and writing followed by 
self-translators, in comparison to Pakistani writers which have the least number of these presentations. However, thought presentation slightly differs in the pattern since self-translators are most frequent with thought presentation, followed by other-translators. Moreover, it can be observed that Pakistani writers have the least number of each presentation category in its corpus. Hence, it can be established by comparing both translator categories with the criterion Pakistani writers that translators as a norm employ more discourse presentation in their translations as compared to Pakistani writers writing original English fiction. Furthermore, other-translators are the most frequent users of discourse presentation as compared to other two text types. In order to elaborate each discourse presentation category further and accentuate differences, a more detailed comparison of speech, thought and writing presentation categories among the three text types is given in the subsections below.

\subsection{Speech Presentation}

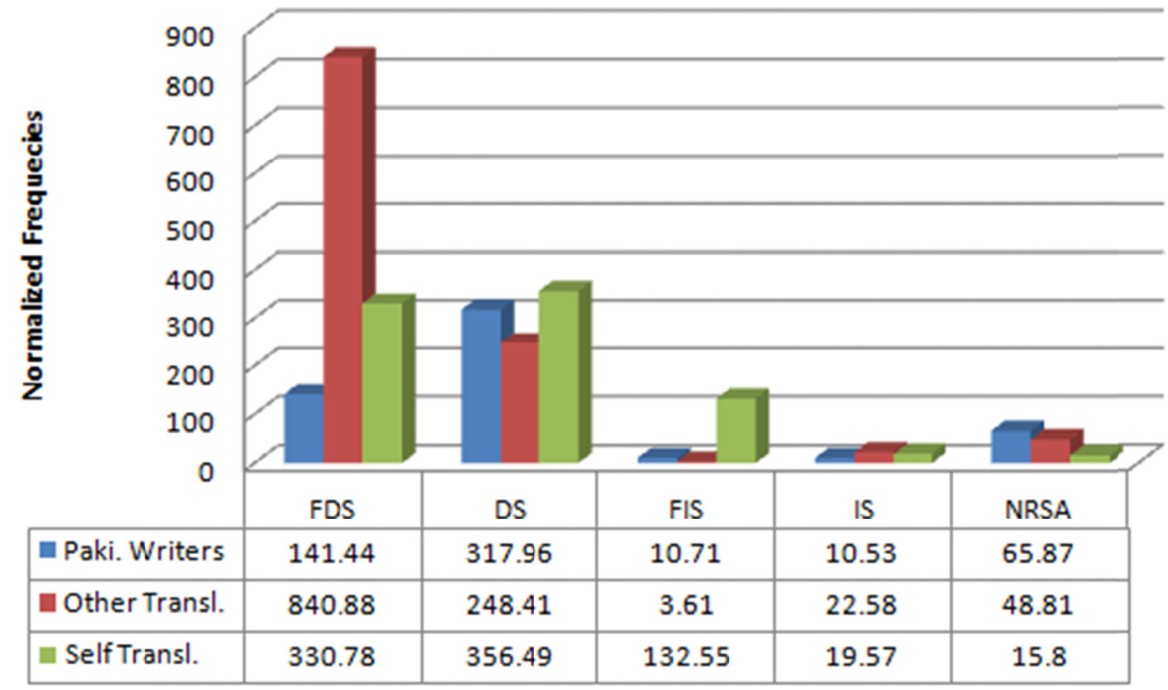

Figure 4. Comparison of speech presentation types across Paki. Writers, Other Transl. and Self Transl

Figure 4 is a comparison of all speech presentation types used in Pakistani writers, other- translators and self-translators. It shows that FDS is the most frequently used form of speech presentation followed by DS. It can also be observed that the bars of DS and FDS fluctuate highly with no evident pattern, however, if DS and FDS are combined as F(DS) (Semino \& Short, 2004) it carries an interpretive value. A visible pattern emerges with other-translators having the highest combined normalized frequency of 1089.29 followed by self-translators with 687.27 whereas Pakistani writers carry the least frequency of 459.4. This endorses the previously mentioned notion that translators use more discourse presentation in their texts. The significance of these frequencies will be elaborated in the next section. This similar pattern is followed in IS where other-translators have a normalized frequency of 22.58, self-translators have 19.57 whereas Pakistani writers use it the least i.e., 10.53. However, these patterns are disturbed in FIS and NRSA. As far as FIS is concerned, it has a strikingly asymmetrical graph where self-translators dominate with a relatively high normalized frequency of 132.55 as compared to other-translators having 3.61 and Pakistani writers with 10.71. This unusual frequency can be explained in terms of the choice of novels where a single novel of this category "The sun that rose from the Earth" contributed highly to the frequency as it was narrated in first person with a past tense, thus, FIS being its major form of discourse presentation. Moreover, NRSA also shows a sort of pattern in its graph where Pakistani writers i.e., the norm has the highest normalized frequency of 65.87 followed by other-translators with 48.81 and self-translators with 15.8 .

From the above mentioned data two major observations can be made. Firstly, in all speech presentation types other-translators always carry a normalized frequency larger than self-translators with the exception of FIS which can be characterized as a separate case. Secondly, both other and self-translators have a frequency either lower or higher than the benchmark i.e., Pakistani writers. This means that Pakistani writers always stand at one extreme of the continuum of each speech type rather than being intermediate except FIS. Hence, it can be said 
that the results of speech presentation category present a fairly discernible pattern that hints towards the style of two translator categories.

\subsection{Writing Presentation}

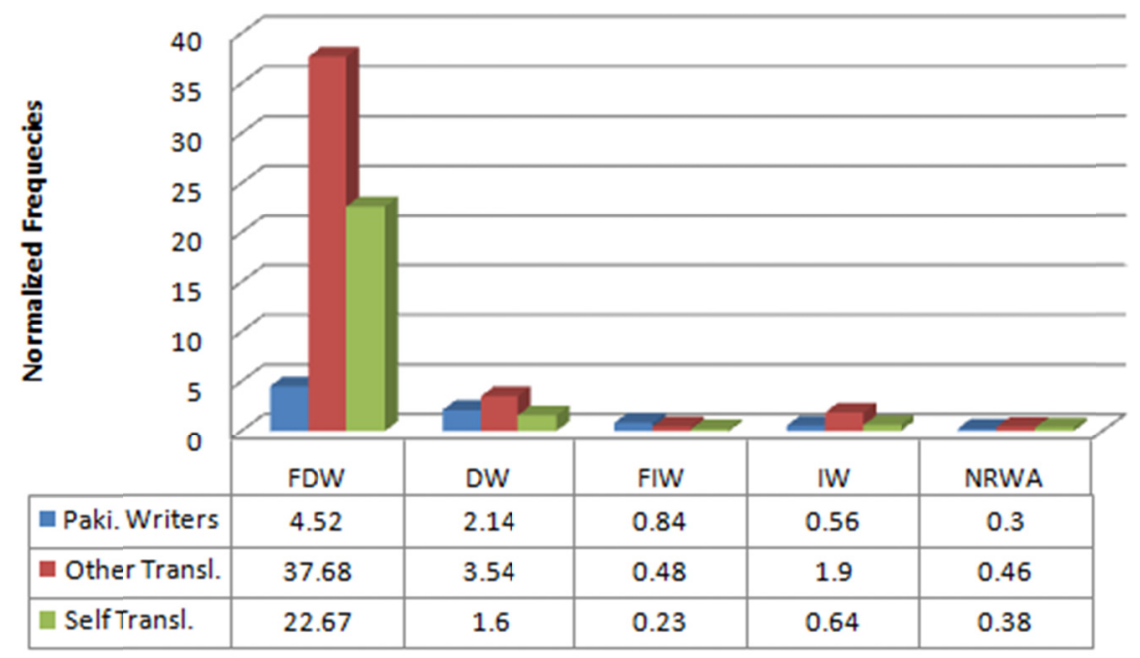

Figure 5. Comparison of writing presentation types across Paki. Writers, Other Transl. and Self Transl

Figure 5 presents a comparative demonstration of all writing presentation types in Pakistani writers, other-translators and self-translators. It depicts that FDW is the most frequently used writing presentation type in the texts, followed by DW. Once again, there is no uniformity in the pattern of use of DW and FDW but when they are combined to F(DW) (Semino \& Short, 2004) a distinct pattern emerges. Hence, the normalized frequency of $\mathrm{F}(\mathrm{DW})$ for other-translators is 41.22 , it is followed by 24.27 for self-translators whereas Pakistani writers in a consistent manner have the lowest frequency of 6.66. Following a similar pattern in IW, other-translators carry a normalized frequency of 1.9; self-translators have 0.64 whereas Pakistani writers have 0.56. Likewise, in NRWA other-translators have a normalized frequency of 0.46 ; self-translators have 0.38 while Pakistani writers have 0.3. Contrarily, FIW is the only type that deviates from these patterns. In FIW, Pakistani writers carry the highest normalized frequency of 0.84 ; other-translators have 0.48 whereas self-translators have the lowest frequency of 0.23 .

It can be observed from the above mentioned results that, firstly, in all writing presentation types other-translators always have the highest frequency followed by self-translators except FIW. Secondly, as a consequence of previous observation, it can be said that Pakistani writers always have the lowest frequency in all writing presentation types except FIW. Thus, as per these results a distinct pattern can be observed in the category of writing presentation quite similar to speech presentation.

\subsection{Thought Presentation}

Figure 6 shows a comparison of all the types of thought presentation in Pakistani writers, other-translators and self-translators. It shows that, unlike speech and writing presentation categories where direct and free direct categories were the highest contributors, every type contributes fairly in thought presentation. It can be observed that FIT has the highest frequencies as compared to other thought presentation types. The reason is that FIT is considered "most frequent of the "canonical" thought presentation categories" (Semino \& Short, 2004, p. 123). As far as DT and FDT are concerned, like previous categories, they show no consistent pattern but when turned into F(DT) (Semino \& Short, 2004) they show a conspicuous pattern, similar to other thought presentation types. Thus, the normalized frequency of F(DT) for self-translators is 36.13 , for other-translators is 29.34 and for Pakistani writers is 4.1. Likewise, in IT, self-translators have the highest normalized frequency of 19.37, followed by other-translators with 16.16 and Pakistani writers with 13.13. Similarly, FIT also follows the same pattern as self-translators have the highest normalized frequency of 38.64, other-translators have 27.68 and Pakistani writers have 13.24. But this pattern is altered in NRTA where, like NRSA, Pakistani writers carry the highest normalized frequency of 22.97; other-translators have 9.69 followed by self-translators with 5.16 


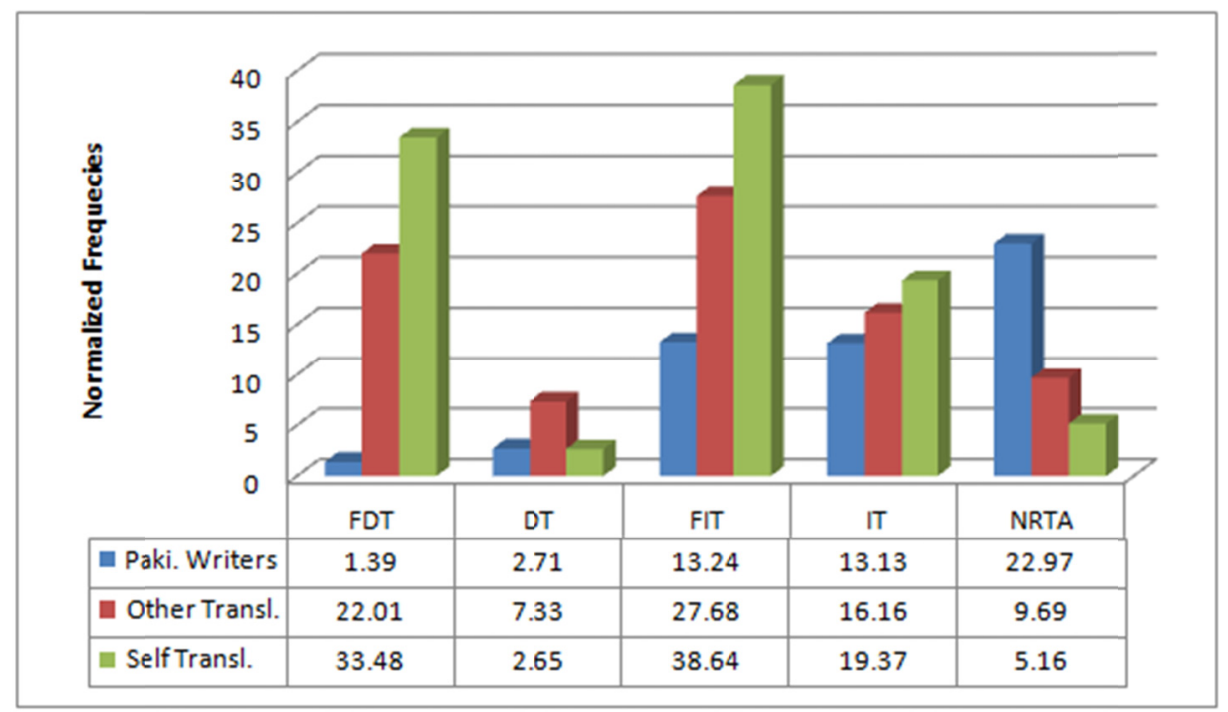

Figure 6. Comparison of thought presentation types across Paki. Writers, Other Transl. and Self Transl

Hence, again two observations can be made out of these results. First of all, in all thought presentation types self-translators always have the highest normalized frequency followed by other-translators except NRTA. Secondly, Pakistani writers category, which acts as a yardstick, has the lowest frequency for all thought presentation types except NRTA. Therefore, the results of thought presentation category are highly significant in mapping the patterns and, hence, style for other and self-translators.

These results will further assist in making interpretations about the effect of these types on point of view of self and other-translators, and it will ultimately determine their peculiar style.

\section{Discussion}

This section will qualitatively analyze our data by keeping in view the quantitative results presented in the previous section. The results of the study show that in comparison to Pakistani writers texts, which act as a point of reference in this research, both other-translators and self-translators use relatively high amount of discourse presentation. It is also found that speech and writing presentation are employed the most by other-translators whereas thought presentation is used the most by self-translators as compared to other text categories in the research. Accordingly, in speech and writing presentation categories, other-translators are the most frequent users of each type except free indirect type i.e., FIS and FIW, and NRSA. Similarly, in thought presentation category, self-translators are the most frequent users of each type except NRTA. Moreover, as an exception, NRSA, NRTA and FIW are the only types in whole discourse presentation which Pakistani writers incorporate the most in their texts as compared to other two text categories.

These results depict a general trend by other and self-translators in the three categories of discourse presentation. By first taking into account speech presentation, the results in figure 2 show that F(DS) is the most frequently used type not only across speech presentation category but across whole discourse presentation. This claim is also supported by Semino and Short (2004) who maintain that "(F)DS is by far the most frequent category of SW\&TP in our corpus" (p. 89). The reason for the frequent use of F(DS), especially in literary texts, is that it adds "dramatization and characterization" (ibid.) which are characteristic of novels. This can be noted in the following example taken from "Godavari":

1) "Silence! Witch!” Ma scolded. Then in frustration she said, "Look Burhki! Whether a chemical reaction is taking place or an atomic explosion, I will not let you carry on any romance here. And marriage! I have told you this not once but a thousand times that first you have to complete your studies and then think of marriage. When we were coming here you promised that you would study. You have failed in the finals and have to appear in the supplementary. Are you going to have people spit on me? My girl failed in the tenth grade!!"

"I will pass the grade Ma," Burhki screamed, "I said so didn't I!"

"Since you have come you have not looked at your books even once. I have lugged a whole suitcase of books up here for you." Ma was really angry. Burhki backed off. 
The italicized sentences in the above example were tagged as DS whereas the emboldened sentence was tagged as FDS as it lacks a reporting clause. Moreover, F(DS) in this example is used to dramatize a scene between mother and daughter on the issue of a boy, it also adds vivacity and portrays the dynamics of mother daughter relationship. Hence, it brings immediacy and closeness of their relationship to the reader.

Considering the frequency of F(DS) in each text category, it can be noted in figure 4 that Pakistani writers have the lowest frequency of F(DS) as compared to the other two text types. The reason for this difference of frequencies can be attributed to translation universals proposed by Baker (1993). As per these universals, translations are more conventional, explicit and simpler than non-translated texts in order to increase their readability. As a result, translators use more marked forms rather than presenting them in complex structures like FIS, where presence of dual voice of narrator and character poses difficulties for the readers. Moreover, most of the studies also show that FID is often converted into direct discourse or sometimes to indirect discourse in translated texts (Kuusi, 2016; Bosseaux, 2004) as "all linguistic changes resulting in the weakening or loss of FID [are] qualified as manifestations of explicitation and normalization" (Kuusi, 2016, p. 13), the two universals of translation. Therefore, other and self-translators use more F(DS) and IS as compared to Pakistani writers. This is the same reason why other-translators use less FIS as compared to Pakistani writers. However, self-translators use the highest amount of FIS which can be considered a deviation from the norm. The reason for this dissent can be attributed to the choice of texts as one novel in self-translators category was responsible for a huge amount of FIS i.e., 129.69 as compared to 0.15 and 2.71 contributed by other two texts. As far as NRSA is concerned, Pakistani writers use it more frequently as compared to other and self-translators whereas F(DS), which lies on the opposite cline of scale, is used more by translator categories. According to McIntyre \& Walker (2011), if NV, which lies next to NRSA on the left side, is over-represented in comparison to F(DS) then "there is more telling (or diegesis) rather than showing (or mimesis)" (p. 118). Therefore, it can be said that that there is more showing (mimesis) rather than telling (diegesis) in translator categories and vice versa in Pakistani writers since it has an over-representation of NRSA, present next to NV on the scale.

All these speech presentation types contribute towards different styles of non-translated and translated texts. As other-translators have higher frequencies of F(DS) and lesser of NRSA and FIS, therefore, they can be said to shift point of view to characters. Moreover, F(DS) has minimum narrator involvement and presents the speech of characters with a certain degree of faithfulness, therefore, it seems to suggest that other-translators try to keep their style objective and more interpretation is required on the part of reader to understand characters. In comparison, non-translated Pakistani writers have a higher frequency of NRSA and FIS as compared to other text types, therefore, they can be said to incline towards narrator's point of view. Hence, it can be hypothesized that Pakistani writers try to keep their style subjective with less interpretation required on the part of reader due to narrator's intervention. As Rimmon-Kenan (1983) also postulated that FID "can assist the reader in reconstructing the implied author's attitude towards the character(s) involved" (p. 114, as cited in Bortolussi \& Dixon, 2003). However, author's attitude can be ironic, thus, creating a distance or emphatic, therefore, creating closeness between characters and readers. As far as self-translators are concerned, they also have an inclination towards characters end of speech (FIS is considered an exception) but since it is less as compared to other-translators, we will leave the discussion of its style till next categories are analyzed in the following paragraphs.

Considering next the findings of writing presentation cline as it is similar to speech presentation category, the results show that other-translators are again the most frequent users of each writing presentation type followed by self-translators except FIW. It can be noticed in figure 5 that $\mathrm{F}(\mathrm{DW})$ is the most used writing presentation type, similar to speech presentation scale. The reason for this difference with Semino \& Short's (2004) fiction corpus where $\mathrm{F}(\mathrm{DW})$ is the second most frequent type and follows NRWA may be attributed to the corpus used. As most of the novels are post-colonial and set in pre-partition India or around that time when people were less connected, the only means of communication being letters, therefore, an epistolary format of writing is employed where letters reveal about the prevalent conditions or characters. The following example taken from "River of Fire" establishes this point:

\section{2) 12th September 1825}

Honored Sir,

I beg to state that I am Maria Teresa Thomas, licencee of "Pagoda Tree", Armenian Street, and I am pleased to inform you that I have now opened Tea Rooms in Ranee Mundy GaleeA wherein the best Chinese beverage is served to August Personages of Calcutta.

The above example can be tagged as FDW as this letter is a direct form of writing by a character and uses no 
inverted commas or reporting clause. Similarly, some of the characters in novels are poets, therefore, verses of poetry also contribute to this high frequency of $\mathrm{F}(\mathrm{DW})$. Following example from "The Sun that Rose from the Earth" demonstrates this:

3) Below it, he quoted a famous line from a ghazal by Hafiz:

The view from the high canopy of my eyes is the place where you are.

The italicized sentence in the above example is a verse from a ghazal which can also be regarded as FDW as it is directly quoted in the text but has no inverted commas or reporting clause.

It can also be observed that similar to DS, DW may also be considered a norm since it represents writing the way it was written; hence, it is the most realistic presentation type for writing. Therefore, high frequency of F(DW) in the corpus shows that translated and non-translated Pakistani writers stick to the norm as they do so in speech presentation. Another argument in support of the frequent use of $\mathrm{F}(\mathrm{DW})$ by translator categories may be attributed again to the universals of translation i.e. the use of explicitation and normalization techniques by translators as mentioned earlier. Since both translator categories use more IW and less FIW in comparison to Pakistani writers, therefore, the argument put forward earlier that FID is converted to direct or indirect discourse in translations offers an explanation for this pattern across these types. As far as NRWA is concerned, the results show that the difference between all three text categories for this type is equal and insignificant, hence can be ignored. This discussion about writing presentation type also shows that other-translators with more $\mathrm{F}(\mathrm{DW})$ then other text categories have an inclination towards character's point of view. Contrarily, Pakistani writers with FIW as the most frequent category in comparison to other texts have an inclination towards narrator's point of view. Moreover, the style of self-translators, again hanging in between other-translators and Pakistani writers, shall be discussed after the explanation of thought presentation category.

Moving on to thought presentation category, the results from figure 3 show that self-translators are the most frequent users of thought presentation in comparison to other types. According to Semino \& Short (2004), as thoughts are personal, an authors' choice to provide access to the thoughts of a character itself "creates a "closeness" that is not normally possible in real life" (p. 124). Therefore, it can be said as a preliminary, that self-translators tend to be more character-oriented as even in the most indirect forms thoughts present the inner workings of mind of characters. Looking now at different types of thought presentation, it can be observed that self-translators have the highest frequency of FIT as compared to other text types. The possible reason for this may be attributed to the notion that as all translations are English translations of the Urdu texts, therefore, translators tend to follow the pattern normally employed in English narrative fiction (target language) i.e. frequency of FIT is the highest among all conventional thought presentation categories. Therefore, translator categories depict an inclination for the norm. Moreover, on a thought presentation scale, FIT is a move towards character's end. As IT is the norm, therefore, frequent use of FIT, which lies to the right of IT, shows that self-translators are more inclined towards character's point of view. Example 4 taken from "River of Fire" presents a sample of FIT:

4) Poor old Kamal was now eighty-five. He held fast to the door. He had grown very feeble but he stood there mustering all his physical strength. He didn't have a sword to defend himself. Slowly he tried to ponder over what these terrible men were saying. He would be taken to Gaur and gaoled, they said. He tried to think of the reason for this punishment. What had he done to be treated thus? He had no quarrel with either the Afghans or the Mughals, he merely wished to be left alone. As though the mere process of living hadn't been tiresome enough! This was his country, his children had been born here, his dear wife lay buried here. He had put all his energy into making these fields bloom, spent years beautifying the language these men were speaking. He had written songs and collected stories and he was going to continue living right here.

The italicized part in the excerpt constitutes FIT. It shows that past tense and third person pronouns are used throughout the example which shows narrator's presence; however, the use of deictics such as "here", "this" and "these" also indicates the presence of character. In contrast, IT presents thoughts of a character from the voice and point of view of narrator.

It can be observed that F(DT) and IT are used the most by self-translators followed by other-translators whereas Pakistani writers employ least of these types. This difference may again be attributed to the notion of translation universals as argued above. However, the pattern differs in NRTA where Pakistani writers have the highest frequency followed by other-translators and self-translators respectively. This again shows Pakistani writers tendency for narrator's point of view whereas the least frequent use by self-translators shows that it shifts point of view to characters rather than narrator. Furthermore, this discussion of thought presentation category maps clear style for the three text categories. In the light of above mentioned arguments, it can be hypothesized that 
self-translators shift point of view to characters but as "in thought acts the voice is always the narrator's, since the character does not make any utterance" (Winters, 2005, p. 50), therefore, it may be suggested that narrators intervene to present and interpret characters thoughts. Contrarily, the style of Pakistani writers tends to be inclined again towards narrator's point of view. Moreover, other-translators have a style intermediate between the two categories in thought presentation but it is closer to self-translators which support previous hypotheses proposed earlier that other-translators shift point of view to characters.

It becomes apparent from the above mentioned arguments that since speech and writing presentation are used the most by other-translators, therefore, these two categories were used to explicate mostly the style of other-translators in comparison to Pakistani writers which acted as a yardstick. Likewise, thought presentation category was used to elucidate the style of self-translators in comparison to Pakistani writers. Moreover, the general styles discussed above for self and other-translators may be considered hypotheses and further verification is required by conducting research that includes different texts from various countries in each text category.

\section{Conclusion}

This research has compared the style of self and other-translators with non-translated texts of Pakistani writers considering discourse presentation as an index of style. The style of these categories has been established on the basis that some discourse presentation categories were over-represented in other translators whereas some categories were disproportionately large in self-translators. The study has found out style differences not only among other and self-translator categories but also depicts that translation categories in general differ extensively in their style from non-translated categories.

The findings show that on speech and writing presentation scale other-translators are the most frequent users and tend to keep their texts towards character's point of view with little interference from narrator (implied author). As a result, the interpretation and understanding of characters lies mostly with the reader, thus, making the style of other-translators a little objective. In a similar way, the findings of thought presentation scale show that self-translators also tend to shift point of view in their texts to characters as thought presentation in itself is a private phenomenon personal to characters. However, further investigation reveals that though self-translators shift their point of view to characters but a little interference from narrator remains a part of all thought presentation types. As a result, its style is distinct from other-translators as thoughts cannot be perceived directly with the exception of IT (norm), where one can tell about his/her thoughts. Therefore, style of self-translators may be characterized as character-oriented which provides an immediacy, characteristic of thoughts, but a little subjective as narrator (implied author) intrudes to guide the reader in order to interpret characters.

As a by-product of this study, the style of non-translated Pakistani writers has also been established. The findings show that Pakistani writers of narrative fiction have a tendency for more narration as compared to translated texts and tilt towards narrator's point of view. This is apparent from the notion that Pakistani writers have the highest frequency only for three discourse presentation types i.e. NRSA, NRTA and FIW and all of them lie on the narrator end of the scale. As a result, style of Pakistani writers in comparison to translators may be attributed as narrator-oriented where characters are given less exposure in order to express their point of view directly.

The results of this study could be useful for researchers interested in the style of self and other-translators as no other previous study has explored their style comparatively. However, it must be mentioned that in order to further generalize these findings regarding style, future researchers might use translated and non-translated texts from authors/translators of different languages to make the findings seem more expansive. As far as the findings of this study are concerned, future researchers might study style of other and self-translators diachronically by collecting translations of last ten years and comparing them with these results in order to evaluate change of style in translations. Thus, the results of this study are also significant for future ventures.

\section{Acknowledgements}

The authors are grateful to Rabia Tabassum, Sadia Shaan and Ammara Khan for their assistance in tagging the texts.

\section{References}

Anthony, L. (2015). AntConc (Version 3.4.4) [Computer Software]. Tokyo, Japan: Waseda University. Retrieved from http://www.laurenceanthony.net/

Baker, M. (1993). Corpus linguistics and translation studies: Implications and applications. In M. Baker, G. Francis \& E. Tognini-Bonelli (Eds.), Text and Technology: In Honor of John Sinclair (pp. 233-250). Amsterdam: John Benjamins. https://doi.org/10.1075/z.64.15bak 
Baker, M. (1995). Corpora in translation studies: An overview and some suggestions for future research. Target, 7(2), 223-243. https://doi.org/10.1075/target.7.2.03bak

Baker, M. (2000). Towards a methodology for investigating the style of a literary translator. Target, 12(2), 241-266. https://doi.org/10.1075/target.12.2.04bak

Bernardini, S. (2007). Collocations in translated language: Combining parallel, comparable and reference corpora. Paper presented at the meeting of Corpus Linguistics Conference, Birmingham, England. Retrieved from http://ucrel.lancs.ac.uk/publications/CL2007/paper/15_Paper.pdf

Bosseaux, C. (2004). Point of view in translation: A corpus-based study of French translations of Virginia Woolf's To the Lighthouse. Across Languages and Cultures, 5(1), 107-122. https://doi.org/10.1556/Acr.5.2004.1.6

Bosseaux, C. I. A. (2004). Translation and narration: A corpus-based study of French translations of two novels by Virginia Woolf. (Doctoral dissertation, University College London, London, England). Retrieved from http://discovery.ucl.ac.uk/id/eprint/1446703

Bosseaux, C. (2007). How does it feel? Point of view in translation: The case of Virginia Woolf into French. Amsterdam \& New York: Radopi.

Bortolussi, M., \& Dixon, P. (2003). Psychonarratology: Foundations for the empirical study of literary response. Cambridge: Cambridge University Press.

Bozkurt, S. S. (2014). Self-translated: Samuel Beckett. In B. Erol (Ed.), One day, Samuel Beckett (pp. 71-81). Ankara: Department of English Language and Literature, Hacettepe University \& the Embassy of Ireland.

Cordingley, A. (2013). Introduction: Self-translation, going global. In A. Cordingley (Ed.), Self-translation: Brokering originality in hybrid culture (pp. 1-10). London \& New York: Bloomsbury.

Ehrlich, S. (2009). Are self-translators like other translators? Perspectives: Studies in Translation Theory and Practice, 17(4), 243-255. https://doi.org/10.1080/09076760903404050

Fitch, B. T. (1988). Beckett and Babel: An investigation into the status of the bilingual work. Toronto: University of Toronto.

Hermans, T. (1996). The translator's voice in translated narrative. Target, 8(1), 23-48. https://doi.org/10.1075/target.8.1.03her

Ho, Y. (2011). Corpus stylistics in principles and practice: A stylistics exploration of John Fowles' The Magus. London \& New York: Continuum.

Huang, L. (2015). Style in translation: A corpus-based perspective (New frontiers in translation studies). Heidelberg: Springer. https://doi.org/10.1007/978-3-662-45566-1_2

Kuusi, P. (2016). Features of discourse presentation in translation: Literary and narratological insights into translation universals. International Journal of Literary Linguistics, 5(3), 1-24. https://doi.org/10.15462/ijll.v5i3.68

Kvantaliani, N. (2014). Variations and effects of speech and thought presentation categories on the basis of short stories by contemporary women writers in English. International Journal of Humanities and Social Science, 4(8), 30-36. Retrieved from http://www.ijhssnet.com/journals/Vol_4_No_8_1_June_2014/4.pdf

Leech, G., \& Short, M. (1981). Style in fiction: A linguistic introduction to English fictional prose. London: Pearson

McIntyre, D., Bellard-Thomson, C., Heywood, J., McEnery, T., Semino, E. \& Short, M. (2004). Investigating the presentation of speech, writing and thought in spoken British English: A corpus-based approach. ICAME Journal: International Computer Archive of Modern and Medieval English, 28, 49-76. Retrieved from http://icame.uib.no/ij28/mcintyre.pdf

McIntyre, D., \& Walker, B. (2011). Discourse presentation in early modern English writing: A preliminary corpus-based investigation. International Journal of Corpus Linguistics, 16(1), 101-130. https://doi.org/10.1075/ijcl.16.1.05mci

McIntyre, D. (2015). Towards an integrated corpus stylistics. Topics in Linguistics, 16, 59-68. https://doi.org/10.2478/topling-2015-0011

Munday, J. (2008). Style and ideology in translation: Latin American writing in English. London \& New York: Routledge. 
Popovič, A. (1976). Dictionary for the analysis of literary translation. Edmonton: Department of Comparative Literature, University of Alberta.

Saldanha, G. (2011). Translator style: Methodological considerations. The Translator, 17(1), 25-50. https://doi.org/10.1080/13556509.2011.10799478

Schiavi, G. (1996). There is always a teller in a tale. Target, 8(1), 1-21. https://doi.org/10.1075/target.8.1.02sch

Searle, J. R. (1976). A classification of illocutionary acts. Language in Society, 5(1), 1-23. https://doi.org/10.1017/S0047404500006837

Semino, E., \& Short, M. (2004). Corpus stylistics: Speech, writing and thought presentation in a corpus of English writing. London \& New York: Routledge.

Snell-Hornby, M., Pochhacker, F. \& Kaindl, K. (1994). Translation studies: An interdiscipline. Amsterdam: John Benjamins. https://doi.org/10.1075/btl.2

Uspensky, B. (1973). A Poetics of composition (trans. Valentina Zavarin). Berkeley: University of California Press.

Vanderveken, D. (1990). Meaning and speech acts: Volume 1, principles of language use. Cambridge: Cambridge University Press.

Venuti, L. (1995). The translator's invisibility: A history of translation. London \& New York: Routledge. https://doi.org/10.4324/9780203360064

Winters, M. (2005). A corpus-based study of translator style: Oeser's and Orth-Guttmann's German translations of F. Scott Fitzgerald's The Beautiful and Damned. (Doctoral dissertation, Dublin City University, Dublin, Ireland). Retrieved from http://doras.dcu.ie/17626/1/Marion_Winters.pdf

\section{Appendix A}

\section{Lists of Speech Act Verbs}

Representative speech act verbs

Assert, reassert, negate, deny, correct, claim, affirm, state, disclaim, declare, tell, suggest, guess, hypothesize, conjecture, postulate, predict, forecast, foretell, prophesy, vaticinate, report, retrodict, warn, forewarn, advise, alert, alarm, remind, describe, inform, reveal, divulge, divulgate, notify, insinuate, sustain, insist, maintain, assure, aver, avouch, certify, attest, swear, testify, agree, disagree, assent, dissent, acquiesce, object, recognize, acknowledge, admit, confess, concede, recant, criticize, praise, blame, accuse, calumniate, reprimand, castigate, denounce, boast, complain, lament.

\footnotetext{
Directive speech act verbs

Direct, request, ask, question, inquire, interrogate, urge, encourage, discourage, solicit, appeal, petition, invite, convene, convoke, beg, supplicate, beseech, implore, entreat, conjure, pray, insist, tell, instruct, demand, require, claim, order, command, dictate, prescribe, enjoin, adjure, exorcise, forbid, prohibit, interdict, proscribe, commission, charge, suggest, propose, warn, advise, caution, alert, alarm, recommend, permit, allow, authorize, consent, invoke, imprecate, intercede.
}

\footnotetext{
Commissive speech act verbs

Commit, pledge, undertake, engage, promise, hypothecate, guarantee, threaten, vow, avow, swear, assure, certify, accept, agree, consent, acquiesce, abide, reject, refuse, renounce, offer, counter-offer, bid, rebid, tender, dedicate, bet, wager, contract, covenant, subscribe.

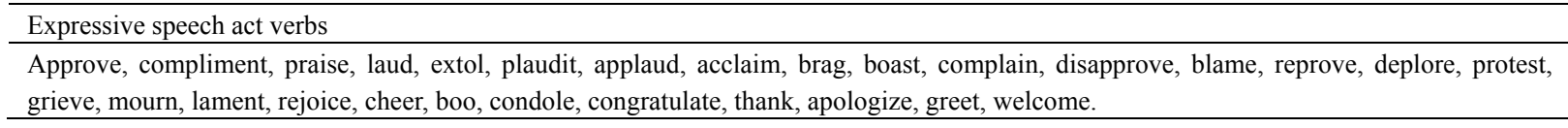

Declarative speech act verbs

Declare, renounce, disclaim, disown, resign, repudiate, disavow, retract, abdicate, abjure, deny, disinherit, yield, surrender, capitulate, approve, confirm, sanction, ratify, homologate, bless, curse, dedicate, consecrate, disapprove, stipulate, name, call, define, abbreviate, nominate, authorize, license, install, appoint, establish, institute, inaugurate, convene, convoke,open, close, suspend, adjourn, terminate, dissolve, denounce, vote, veto, enact, legislate, promulgate, decree, confer, grant, bestow, accord, cede, rule, adjudge, adjudicate, condemn, sentence, damn, clear, acquit, disculpate, exonerate, pardon, forgive, absolve, cancel, annul, abolish, abrogate, revoke, repeal, rescind, retract, sustain, bequeath, baptize, excommunicate.
} 


\section{Copyrights}

Copyright for this article is retained by the author(s), with first publication rights granted to the journal.

This is an open-access article distributed under the terms and conditions of the Creative Commons Attribution license (http://creativecommons.org/licenses/by/4.0/). 